\title{
TWITTER NA EDUCAÇÃO: PESQUISANDO NAS E COM AS REDES SOCIAIS DIGITAIS
}

\author{
Edméa Santos ${ }^{1}$ \\ Gabriela Ozório 2
}

Resumo: Este artigo é parte integrante da pesquisa sobre Redes Sociais Digitais na Educação realizada pelo GPDOC - Grupo de Pesquisa Docência e Cibercultura, do Programa de Pós-Graduação em Educação (PROPED) da Universidade do Estado do Rio de Janeiro - UERJ. 0 objetivo deste texto é apresentar uma contribuição para a temática Redes Sociais na Educação, tendo como objeto de estudo o Twitter, um software de microblog que vem estruturando redes sociais e de aprendizagem na internet. Neste trabalho, apresentamos o Twitter não só como um software social, mas também como um campo fecundo de pesquisa e formação. Para tal, optamos pela abordagem multirreferencial (ARDOINO, 1998) com imersão na interface, tendo como dados os tweets publicados por alguns dos mais importantes pesquisadores da área da Cibercultura, nos meses de outubro/novembro de 2010. Para analisá-los, as pesquisadoras realizaram uma leitura interpretativa das mensagens, a fim de perceber significados e recorrências, que constituíram as noções subsunçoras, apresentadas aqui como categorias representativas desses usos (MACEDO, 2008). São elas: o uso do Twitter para a comunicação entre sujeitos geograficamente dispersos, o uso para tornar público os relatos do cotidiano, o uso como filtro de informação e o uso para discussão sobre temas específicos. A partir destes usos, entendemos que o Twitter pode estruturar processos de construção colaborativa do conhecimento por meio de algumas potencialidades comunicacionais da interface, dentre as quais podemos citar: a comunicação multidirecional, o compartilhamento de informação e a constituição de comunidades.

Palavras-chave: Educação. Cibercultura. Redes Sociais. Twitter.

1 Professora Titular-Livre da Universidade Federal Rural do Rio de Janeiro, do Programa de PósGraduação em Educação da UFRRJ e do Programa de Pós-Graduação em Educação da UERJ. Coordenadora do Grupo de Pesquisa Docência e Cibercultura (GPDOC).

2 Mestranda do Programa de Pós-Graduação em Educação da PUC-Rio e Membro do Grupo de Pesquisa Docência e Cibercultura (GPDOC).E-mail: gabrielagoncalvesx@gmail.com 


\title{
TWITTER IN EDUCATION: SEARCHING IN AND WITH DIGITAL SOCIAL NETWORKS
}

\begin{abstract}
This article is part of the research on Digital Social Networks in Education conducted by GPDOC - Teaching and Cyberculture Research Group, of the Graduate Program in Education (PROPED) of the State University of Rio de Janeiro - UERJ. The purpose of this paper is to present a contribution to the theme Social Networks in Education, with the object of study Twitter, a microblogging software that has been structuring social and learning networks on the Internet. In this paper, we present Twitter not only as social software, but also as a fruitful field of research and training. For this, we opted for the multi-reference approach (ARDOINO, 1998) with immersion in the interface, taking as data the tweets published by some of the most important researchers in the area of Cyberculture, in October/November 2010. To analyze them, the researchers performed an interpretative reading of the messages, in order to understand meanings and recurrences, which constituted the subsuming notions, presented here as representative categories of such uses (MACEDO, 2008). They are: the use of Twitter for communication between geographically dispersed subjects, the use to make public the reports of daily life, the use as an information filter and the use for discussion on specific topics. From these uses, we understand that Twitter can structure processes of collaborative construction of knowledge through some communicational potentialities of the interface, among which we can mention: multidirectional communication, information sharing and community building.
\end{abstract}

Keywords: Education. Cyberculture. Social Networks. Twitter.

\section{TWITTER EN EDUCACIÓN: BÚSQUEDA EN Y CON REDES SOCIALES DIGITALES}

Resumen: Este artículo es parte de la investigación sobre Redes Sociales Digitales en Educación realizada por GPDOC - Grupo de Investigación en Docencia y Cibercultura, del Programa de Posgrado en Educación (PROPED) de la Universidad Estatal de Rio de Janeiro - UERJ. El propósito de este trabajo es presentar una contribución al tema Redes sociales en educación, con el objeto de estudiar Twitter, un software de microblogging que ha estado estructurando redes sociales y de aprendizaje en Internet. En este artículo, presentamos Twitter no solo como software social, sino también como un campo fructífero de investigación y capacitación. Con este fin, optamos por el enfoque multirreferencial (ARDOINO, 1998) con inmersión en la interfaz, teniendo como datos los tweets publicados por algunos de los investigadores de cibercultura más importantes, en los meses de octubre/noviembre de 2010. Para analizarlos, los investigadores realizaron una lectura interpretativa de los mensajes, para comprender los significados y las recurrencias que constituían los conceptos subsumidores, presentados aquí como categorías representativas de estos usos (MACEDO, 2008). Ellos son: el uso de Twitter para la comunicación entre temas geográficamente dispersos, el uso para hacer públicos los informes de la vida cotidiana, el uso como filtro de información y el uso para la discusión sobre temas específicos. A partir de estos usos, entendemos que Twitter puede estructurar procesos de construcción colaborativa de conocimiento a través de algunas potencialidades comunicativas de la interfaz, entre las cuales podemos mencionar: comunicación multidireccional, intercambio de información y desarrollo comunitario.

Palabras clave: Educación. Cibercultura. Redes sociales. Twitter 


\section{Entrando na Rede: cibercultura em tempos de web 2.0 e redes sociais}

Vivemos um cenário que evidencia principalmente mudanças na sociabilidade e na vida cotidiana, e estas, já sabemos, estão vinculadas à revolução tecnológica provocada pelas novas tecnologias da informação e comunicação. Tais mudanças tornaram possível o desenvolvimento e a consolidação de uma nova cultura, que chamamos de Cibercultura. Santos (2009, p. 6) define a Cibercultura como "a cultura mediada pelas tecnologias digitais, em que seres humanos em rede interagem com as tecnologias, afetando-se mutuamente”. Já Lévy (1999, p. 17) a define como "o conjunto de técnicas (materiais e intelectuais), de práticas, de atitudes, de modos de pensamento e de valores que se desenvolvem juntamente com o crescimento do ciberespaço". Para o mesmo autor, o ciberespaço "não é apenas a infraestrutura material da comunicação digital, mas também os seres humanos que navegam e alimentam esse universo".

Dentre as diversas tecnologias da informação e comunicação, apontamos 0 computador e a internet como os principais aparatos desse processo. A internet se constitui como uma rede global, através da qual a Cibercultura se desenvolve. $\mathrm{Na}$ primeira fase da internet, conhecida como web 1.0, os usuários não dispunham de interfaces amigáveis para a produção e o compartilhamento de conteúdo. Além disto, era necessário que este indivíduo conhecesse linguagem específica de programação como, por exemplo, HTML, para exercer sua autoria no ciberespaço. Desta forma, grande parte dos usuários comuns da internet a utiliza apenas para “saquear" informação, quase como uma grande enciclopédia.

Com a expansão do acesso à rede mundial de computadores e do surgimento de novas combinações de técnicas informacionais, vivenciamos a chegada de uma segunda geração de serviços, que chamamos de Web 2.03. Tal fenômeno refere-se à expansão de acesso da internet a novos grupos mais ligados a lógica de interativade e a idéia do "faça você mesmo". Para surgimento de novas atitudes de

3 A expressão "Web 2.0" tornou-se conhecida e destacada mundialmente a partir da publicação em 2005 do artigo “O que é Web 2.0", por Tim 0’Reilly (2005). 
autoria e co-autoria no ciberespaço foi necessária uma permanente evolução das interfaces ${ }^{4}$. Primo (2007) destaca que esse fenômeno:

tem repercussões sociais importantes, que potencializam processos de trabalho coletivo, de troca afetiva, de produção e circulação de informações, de construção social de conhecimento apoiada pela informática (PRIMO, 2007, p.15).

Com o desenvolvimento da Web 2.0, presenciamos o surgimento de um novo tipo de software social: os softwares de redes sociais. De acordo com Recuero (2009a, p.102), são nesses espaços que percebemos as expressões das redes sociais na internet. Como exemplos podem citar o Mylastfm, Orkut, Myspace, Facebook, Twitter, entre outros.

Nesse contexto, o GPDOC - Grupo de Pesquisa Docência e Cibercultura - tem como objetivos: investigar os fenômenos sociotécnicos e culturais mediados pelas tecnologias digitais da informação e comunicação e suas implicações para os processos de aprendizagem e docência; desenvolver metodologias de pesquisa e projetos de ensino e aprendizagem que aproximem o currículo escolar das práticas comunicacionais na cibercultura; desenvolver currículos e atos de currículos para o exercício da docência online; compreender como as interfaces digitais podem contribuir para a produção e gestão do conhecimento.

Assim, desenvolvemos estudos e projetos sobre a docência na contemporaneidade e as práticas e processos da cibercultura, em especial a educação online e os processos de ensino e aprendizagem em espaços multirreferenciais de aprendizagem. Articulamos as áreas de educação, comunicação e informática. Nosso principal engajamento é com a formação de pesquisadores e docentes em processos de formação inicial e continuada.

Esse texto é produto da pesquisa intitulada "A cibercultura ma era das redes sociais e da mobilidade: novas potencialidades para a formação de professores”, que procura compreender os usos que docentes e pesquisadores têm feito das redes sociais e da mobilidade ubíqua em seus processos de aprendizagem e formação (SANTOS, 2010a). Deste modo, este texto apresenta uma contribuição para a temática, tendo como objeto de estudo o Twitter, um software de microblog

4Para Lévy (1999, p. 37), interface são todos os aparatos materiais que permitem a interação entre o universo da informação digital e o mundo ordinário. 
que vem estruturando redes sociais e de aprendizagem na internet. Neste trabalho, apresentamos o Twitter não só como um software social, mas também como um campo fecundo de pesquisa e formação.

\section{Twitter: da inteface de microblog e rede social a campo de pesquisa multirreferencial}

O Twitter foi criado em 2006 pela empresa Obvious. Inicialmente, foi utilizado como ferramenta de comunicação interna da empresa, porém percebendo 0 potencial comuncacional e interativo da interface, seus dirigentes decidiram colocá-lo a disposição dos internautas em agosto do mesmo ano.

As características da interface do Twitter derivam-se do contexto da Web 2.0, na qual os conceitos de participação e colaboração foram explorados ao máximo em novos formatos de páginas dinâmicas que podem ser fáceis e constantemente renovadas. Dentre os novos formatos de página, o Twitter é considerado um microblog. De acordo com Zago (2008, p. 7), microblogs são as interfaces "de blogs mais simplificadas, voltadas para postagens com limitações de tamanho, e muitas vezes associadas à idéia de mobilidade” Orihuela (apud Zago, 2008) complementa que os microblogs são a "mistura de blog com rede social e mensagens instantâneas”.

Martins e Aguiar (2009) explicam as diferenças entre blogs e microblogs quanto ao espaço disponibilizado:

Os blogs oferecem a possibilidade de agregar imagens, áudio, vídeo, gadgets de outros sites, entre outros recursos que implicam em páginas multimídia. 0 conteúdo por postagem é ilimitado: 0 autor pode escrever o quanto quiser e ilustrar com tantas imagens, áudios e vídeos quanto achar necessário. Já o Twitter limita cada postagem a 140 caracteres de texto escrito. Os links é que levam a outros espaços onde estarão textos maiores, fotos, vídeos e músicas (MARTINS; AGUIAR, 2009, p. 10).

Os mesmos autores ainda destacam outras diferenças, quanto à aparência, o blog permite maior flexibilidade, na qual o autor personaliza a página de acordo com a sua vontade, já o Twitter não possui tanta flexibilidade, pois todos os usuários dispõem das mesmas interfaces que não podem ser excluídas nem 
modificadas. Quanto ao perfil, à diferença permanece no tamanho da mensagem, o blog permite um perfil mais detalhado e o microblog algo mais sucinto e direto. Além disto, Martins e Aguiar (2009) apontam que a espontaneidade é maior no microblog, pois no blog existe uma maior preocupação com a relevância e a repercussão do que vai ser postado, o que nos leva a caracterizar o microblog como uma interface mais instantânea e imediata.

Após 11 anos da sua criação, o Twitter passou por certas mudanças em sua interface. 0 que começou permitindo apenas a postagem de textos e links totalizando até 140 caracteres por mensagem, hoje a ferramenta de microblog permite maior mixagem de mídias, suportando a postagens de vídeos, imagens, gifs animados, enquetes, emoticons ${ }^{5}$ relacionados aos 140 caracteres iniciais.

Todas estas características contribuem para que a interface estruture redes sociais, através da associação de pessoas com interesses em comum que interagem colaborativamente a partir da mediação tecnológica das redes e de suas conexões.

As redes sociais na internet são constituídas de atores e conexões. Quando os atores interagem com outros atores formam-se as conexões. $\mathrm{Na}$ comunicação mediada pelas tecnologias digitais, os atores são identificados a partir de suas representações identitárias no ciberespaço, ou seja, os atores são representados por sua conta do Twitter ou mesmo por um perfil no Orkut.

Neste sentido, as redes sociais na internet podem ser compreendidas como:

novas formas de comunicação e interação nas quais o indivíduo pode criar perfis, encontrar e reencontrar amigos, divulgar eventos, notícias etc. Elas se tornaram instrumentos de comunicação amplamente utilizados como um espaço imaterial de sociabilidade, manifestações de protestos, difusão de informação, definição de agendas, compartilhamentos de experiências e conhecimentos (CARRANO, 2017, p. 400).

Deste modo, o Twitter é um software que tem dinamizado interações em rede a partir do uso de computadores conectados e de dispositivos móveis. As atualizações de cada usuário ficam disponíveis na sua página pessoal e também

5 É uma palavra derivada dos seguintes termos em inglês: emotion (emoção) + icon (ícone); uma pequena imagem ou alguns caracteres tipográficos que traduzem ou quer transmitir o estado psicológico, emotivo, de quem os emprega, por meio de ícones ilustrativos de uma expressão facial. 
são enviadas a outros usuários que 0 seguem (followers ${ }^{6}$ ). Elas podem ser conferidas pelo site, por $\mathrm{RSS}^{7}$, por $\mathrm{SMS}^{8}$ ou por algum aplicativo derivado. Esta característica possibilita ao usuário atualização de conteúdo em tempo real de qualquer lugar em que ele se encontre. A partir de suas peculiaridades, o Twitter torna possível:

que pessoas de diferentes culturas troquem informações, não somente entre si, mas também com celebridades, mídias e organizações as mais diversas, de forma simultânea, particularizada e em tempo real, sem que haja os tradicionais filtros ou instâncias hierarquizantes a controlar os diálogos virtuais. Nesse sentido, as informações transitam entre mídias de todas as espécies, aliadas aos sistemas de comunicação interpessoal, em uma multiplicidade de conexões personalizadas e selecionadas pelos próprios usuários (NICOLAU, 2009, p. 2).

\section{Metodologia}

Nesta fase da pesquisa, optamos por mapear e analisar como alguns dos docentes e pesquisadores da Cibercultura estão utilizando esta interface em seus cotidianos. Esses sujeitos são membros da $A B C I B E R^{9}$ - Associação Brasileira de Pesquisadores em Cibercultura - cuja missão principal é congregar pesquisadores (as), grupos de pesquisa, instituições e/ou entidades brasileiras em torno de temáticas pertinentes ao campo de estudos sobre o fenômeno da Cibercultura (nos termos de seu Estatuto); e de nuclear e consolidar esse campo interdisciplinar de estudos, contribuindo para o desenvolvimento científico, tecnológico e cultural do país. (ABCIBER, 2010)

A escolha pelo grupo da Abciber deu-se pela razão que estes sujeitos já estão imersos na lógica da Cibercultura, são autores e co-autores do cenário. E também são pesquisadores das "múltiplas relações entre as tecnologias/redes digitais e a vida social, cultural, política e econômica contemporânea” (ABCIBER, 2010).

6 São os usuários que estão seguindo sua conta no Twitter. Quando um usuário está te seguindo, ele recebe todas as suas atualizações na página principal do site.

7 É uma tecnologia que serve para agregar conteúdo, que pode ser acessada mediante programas ou sites agregadores. Usada principalmente em sites que mudam ou atualizam o seu conteúdo regularmente.

8É a abreviação de serviço de mensagens curtas. Disponível em alguns telefones (celulares), sua principal função é envio de mensagem de texto através de redes de comunicação sem fio.

9 Para mais informações, ver: http://abciber.org/ 
Utilizamos como metodologia a abordagem multirreferencial com imersão na interface Twitter, em que seguimos e interagimos com alguns dos mais importantes pesquisadores da área. Concordamos com Santaella e Lemos (2010, p. 318), para quem “a imersão pressupõe o conceito de interface, quer dizer, a membrana inteligente que permite a entrada e negociação dialógica em ambiente virtual”. Nesse sentido, utilizamos o Twitter com a intenção de vivenciar a comunicação ubíqua em rede, prática cultural do grupo em outros contextos, mas também, e sobretudo, produzir usos e conteúdos com e por essas mediações, forjando assim um dispositivo formativo coletivo, colaborativo e em rede (SANTOS, 2012).

A abordagem multirreferencial nos esclarece as riquezas da prática social, sem a fragmentação da análise clássica, por meio da decomposição-reduzação dos objetos. Ela permite entender essas práticas ao invés de tentar explicá-las. Assim é possível entendê-los a partir de olhares outros, sem desejar formar uma verdade única, mas fazendo valer fatos ignorados pela ciência moderna, como a relação do pesquisador com os atores e com o objeto. Ardoino (1998) esclarece que:

a multirreferencialidade não quer fornecer uma resposta à complexidade constatada com a qual permanece intimamente ligada, ou tornar sua leitura dirigida, por assim dizer, mas constitui muito mais o apelo deliberado através da pluralidade de olhares e de linguagens, reconhecidos como necessários à compreensão dessa suposta complexidade, de um questionamento epistemológico, atualmente imprescindível nessas áreas, antecessor de toda operacionalição de métodos e de dispositivos (ARDOINO, 1998, p. 41).

Sabemos que a construção e edificação de saberes docentes é um movimento plural. Não aprendemos apenas na escola e na universidade. Estes espaços são responsáveis pela edificação de saberes científicos e disciplinas, saberes fundamentais para o exercício da docência. Entretanto, precisamos habitar e vivenciar outros espaços multirreferenciais de aprendizagem. A epistemologia da multirreferencialidade (ARDOINO, 1998) parte do princípio de que os saberes precisam ser articulados e vivenciados na pluralidade de suas construções e instituições. 0 saber científico não é o centro do processo. É mais um importante 
saber. Este, na cena formativa, deve articular-se com os saberes do cotidiano, das artes, da filosofia.

$\mathrm{Na}$ grande maioria dos projetos de formação de professores temos a centralização do saber científico em detrimento aos saberes construídos na cultura, na vida cotidiana das cidades, das mídias, no exercício da docência. Quando tratamos do objeto "tecnologias e educação" o problema se agrava. A grande parte dos atos de currículo é centralizada no uso instrumental e científico e quase nunca observamos a vida social instituída por estas tecnologias. Além de estudar as tecnologias em si, precisamos adentrar na vida social estruturada por elas para entendermos como os sujeitos do cotidiano edificam seus saberes e a própria cultura sociotécnica (SANTOS, 2010b).

Assim, procuramos investir em pesquisas que concebam o ciberespaço também como um campo fecundo de pesquisa. Neste trabalho interagimos no e com o Twitter. Os dados desta fase são constituídos pelos tweets publicados por estes sujeitos, nos meses de outubro/novembro de 2010. Para analisá-los, as pesquisadoras realizaram uma leitura interpretativa das mensagens, a fim de perceber significados e recorrências, que constituíram as noções subsunçoras, apresentadas aqui como categorias representativas destes usos. Esta forma de organizar a análise da pesquisa exige do pesquisador competências teóricoanalíticas e compreensão sobre a realidade pesquisada para evitar a decomposiçãoredução citada acima (MACEDO, 2008).

\section{Achados da pesquisa: os ciberpesquisadores no Twitter}

Durante o período da imersão, percebemos a recorrência do uso deste software para a comunicação entre sujeitos geograficamente dispersos, conforme os tweets abaixo. 
Figura 1 - Espaço para Comunicação entre sujeitos geograficamente dispersos

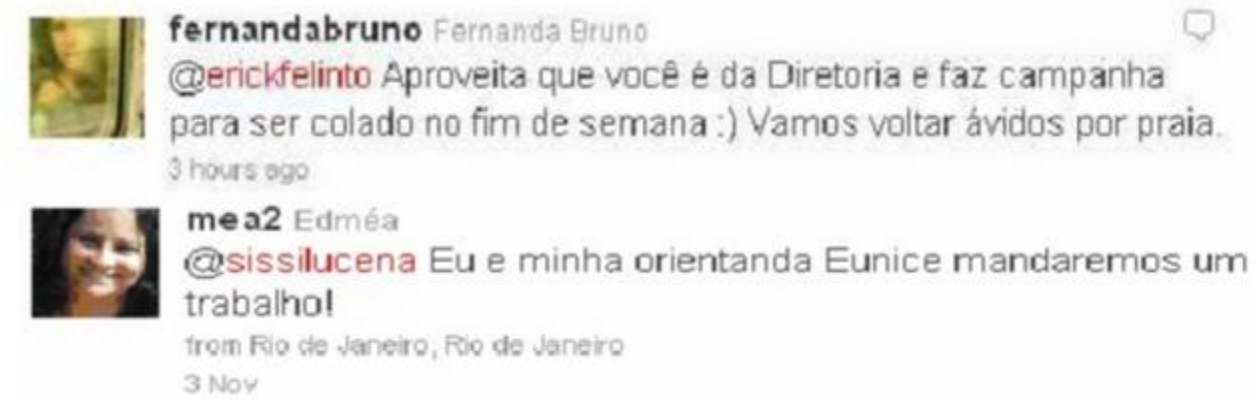

Fonte:Twitter @fernandabruno e @mea2.

De certo, o recurso reply ${ }^{10}$ permite que os sujeitos se comuniquem de forma instantânea, através dos tweets. Entretanto, é interessante observar que esta comunicação possui outra dimensão, pois mesmo que o recurso reply facilite a relação unidirecional, no Twitter, apesar da possibilidade de proteção dos tweets, todos os sujeitos, seguidores ou não, tem acesso aos tweets abertos. Isto é, quando um sujeito publica um tweet, outro sujeito que tenha acesso à conta do primeiro, poderá dar um reply e continuar a conversa inserindo informações novas, criticando opiniões e problematizando as mensagens. Desta maneira, a comunicação torna-se multidirecional (todos-todos), descentralizada, multifacetada, permitindo que qualquer um entre no assunto, acrescente comentários ou informações.

Vale ressaltar que tal liberação do pólo de emissão, só se tornou possível após a expansão da internet comercial nos anos 90. Lemos (2002) destaca que este momento foi propício também ao escoamento de discursos pessoais no ciberespaço. Percebemos ao analisar algumas características da interface do Twitter que este software incentiva a sua apropriação para relatos do cotidiano.

Pois, inicialmente, o microblog apresentava a seguinte pergunta na página pessoal dos usuários: “O que você está fazendo?” ${ }^{11}$. Este questionamento condicionou os diversos sujeitos a apropriaram-se do Twitter como espaço para relatos do cotidiano, como verificamos a seguir.

10 Recurso utilizado para responder diretamente a outro usuário do Twitter. Para isto, basta introduzir o nome do usuário precedido de “@” e posteriormente escrever a mensagem. 11Tradução das autoras para “What are you doing?”. 
Figura 2 - Espaço de Relatos do Cotidiano

to

alexprimo

O fantástico show do Paul Mccartney ontem em Porto Alegre foi 0

melhor presente de aniversário (hoje) que já recebil

8 Noy

6. mear2 Edméa

Cena histórica na EduUerj. Tirando os plásticos dos computadores

para acessar a rede na sala 12050 \#TwitPict

hittn//thwitnic com/35iavu

sibenei Bimone Pereira de 8a

Bom almaçar em casa. Em especial pela soneca de 15 min que

vou tirar agora, pra depois partir feliz pro LabCult :)) 23 hours ago

Fonte:Twitter@alexprimo, @mea2 e @sibonei.

Assim, tornou-se comum dizer tudo o que está fazendo, pensando, comendo, ou seja, tornar pública todo a sua rotina. 0 que acabou ocasionando a mudança desta pergunta para "0 que está acontecendo?"12.

0 que vivenciamos, neste cenário, é passagem da escrita sobre si do papel e dos diários pessoais para o ciberespaço. Essa passagem tornou a escrita sobre si em algo público e que no caso do Twitter, pode ser atualizada constantemente de qualquer lugar e em tempo real. Estas últimas características evidenciam uma das potencialidades deste software social: a comunicação síncrona. Sobre tal passagem, Lemos (2002, p. 7) completa que "no ciberespaço, o público e privado se confundem como nunca, e os usuários experimentam um exercício de emissão e de construção de representações identitárias, abolindo as fronteiras entre eles e o mundo". Desta maneira,

a vida comum transforma-se em algo espetacular, compartilhada por milhões de olhos potenciais. E não se trata de nenhum evento emocionante. Não há histórias, aventuras, enredos complexos ou desfechos maravilhosos. Na realidade, nada acontece a não ser a vida banal, elevada ao estado de arte pura. A vida privada, revelada por diários pessoais, é transformada em um espetáculo para olhos curiosos, e este espetáculo é a vida vivida na sua banalidade radical (LEMOS, 2002, p. 12).

Neste ponto é interessante destacar que no Twitter a construção de representações identitárias ocorre através dos laços e interações estabelecidas (RECUERO, 2009b) e ela é sempre provisória, devido às funcionalidades de seguir e

12 Tradução das autoras para “What's happening?”. 
não seguir (follow e unfollow). Sendo assim, devido ao caráter instantâneo das mensagens, é possível que um sujeito queira acompanhar determinado assunto que está sendo abordado e minutos depois não deseje mais. Por exemplo, enquanto um sujeito está twittando sobre um evento acadêmico que eu não pude comparecer presencialmente, posso segui-lo (follow) para acompanhar e interferir nas discussões, tão logo o evento acabe, eu posso deixar de segui-lo (unfollow) ou posso estabelecer um laço devido às interações realizadas anteriormente.

Este estabelecimento de laços e interações entre os sujeitos também permitiu a emergência de um outro uso deste software social: 0 uso do Twitter como filtro de informação, já que nele encontramos grande divulgação de links para reportagens, eventos e artigos. Assim, seguindo certo sujeito podemos ter acesso a todo tipo de link divulgado por ele. Esta noção aponta uma das mais importantes potencialidades deste software social: o compartilhamento de informação.

Figura 3 - Espaço de Filtro de Informação

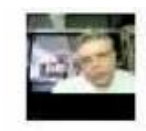

andrelemos André Lemos

Publicado"@re_vira_volta. Uma experiência em Twitteratura",

fiç̧ăo que nasceu no Twitter. e-book pela Simplissimo. http://bit.ly/azGZ25

अ Oot

政

sissilucena simone Lucena

| Simposio Regional Educaçắo / Comunicação - 29/11 a 01/12 na

Unit - Aracaju-SE - http //Mmw ead unit.br/simposioregional 3 Nov

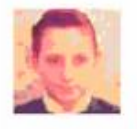

nlpretto Nelson Pretto

seminário no Itamaraty "Crianças e internet" Vale conferir em

http//culturadigital.br/gisi/criancas/

$10 \mathrm{Now}$

Fonte: Twitter @andrelemos, @sissiluena e @nlpretto.

Se antes do sugimento das redes socias, a filtragem de informação através de mecanismos de busca demandava tempo e sensibilidade para selecionar o que é e o que não é informação confiável. Hoje, conforme Nicolau (2009),

as informações através de links, no Twitter, já vêm com certo crivo de quem o está indicando, a partir de um discernimento contextualizado. São indicações de fontes de saberes fornecidos por pessoas de nossas áreas de interesse que se mostram confiáveis ao longo das relações no próprio Twitter, fazendo com que passemos a segui-las diariamente (NICOLAU, 2009, p. 2). 
0 processo de filtragem tornou-se mais simples através das diversas conexões entre os sujeitos das redes sociais, e foi também, através dessas conexões e de recursos como o retweet ${ }^{13}$ que o compartilhamento de informações em rede tornouse infinito. Para Recuero (2009b), "as informações tratam-se de um bem de valor e por isso, os sujeitos selecionam - ainda que com critérios próprios - o que deve ser passado à sua rede de seguidores (followes) e o que não deve”.

Nesse sentido, as autorias dos ciberpesquisadores podem chegar a outros espaços, o que antes das redes sociais online não aconteceria, tornando possível a circulação e cooperação científica.

Encontramos no Twitter, outro recurso que pode auxiliar na busca de informações sobre determinado assunto. As hashtags ${ }^{14}$ são etiquetas usadas e criadas pelos sujeitos para agregar e identificar diversos tweets sobre um mesmo tema. Em geral, é uma frase ou palavra precedida do símbolo “\#”. Sua finalidade pode ser enfatizar um tweet ou facilitar a localização de tweets sobre um mesmo tema, mas também pode não ter nenhum objetivo e até ser usada por brincadeira.

No Brasil, diversas hashtags foram criadas e acabaram entrando para 0 Trending Topics ${ }^{15}$, dentre elas podemos citar: \#forasarney - quando os usuários do Twitter uniram-se para pedir a saída de José Sarney do Senado; \#cparty - marca utilizada para comentários sobre o famoso evento mundial nerd Campus Party e \#prontofalei - que é utilizada para relatar desabafos.

Deste modo, aqui encontramos outra potencialidade do twitter: a constituição de comunidades. Neste ponto é importante destacar que embora a interface do Twitter não possua nenhum espaço próprio para constituição de comunidades, como o Orkut, as comunidades tomam forma em torno dos interesses e das relações e interações sociais estabelecidas via Twitter.

De acordo com Santaella e Lemos (2010, p. 113), o Twitter constitui-se "como uma ecologia de comunidades integradas em um ecossistema flexível, na qual

13Recurso para repassar o conteúdo de um tweet de outro usuário, mas reconhecendo este como a fonte da informação.

14Hashtags é o conjunto de tags aplicada em algum tweet enviado ao Twitter, para classificar o assunto da mensagem em uma espécie de "categoria".

15 Espécie de ranking dos assuntos que foram mais abordados no Twitter em um determinado período. 
comunidades são formadas e dissolvidas à medida que o interesse por um tema específico aumenta ou diminui”.

As mesmas autoras ainda complementam que:

diversos tipos de comunidades podem existir simultaneamente, algumas mais permanentes que outras. Cada usuário possui duas comunidades permanentes que tendem a mudar lentamente com o tempo: sua comunidade de seguidores, e a comunidade daqueles a quem o usuário segue. Outras comunidades, porém, surgem e desaparecem a todo instante através do uso de hashtags, que formam comunidades temporárias de usuários interessados no acompanhamento de um tema específico (SANTAELLA; LEMOS, 2010, p. 113).

Entre os sujeitos da nossa pesquisa é comum verificarmos a formação de comunidades através do uso do recurso das hastags para discussão sobre temas específicos, seja marcando dia e horário com seus alunos/seguidores ou apenas publicando comentários e acontecimentos sobre os eventos acadêmicos, conforme podemos visualizar abaixo.

Figura 4 - Hastags para discussão sobre temas específicos

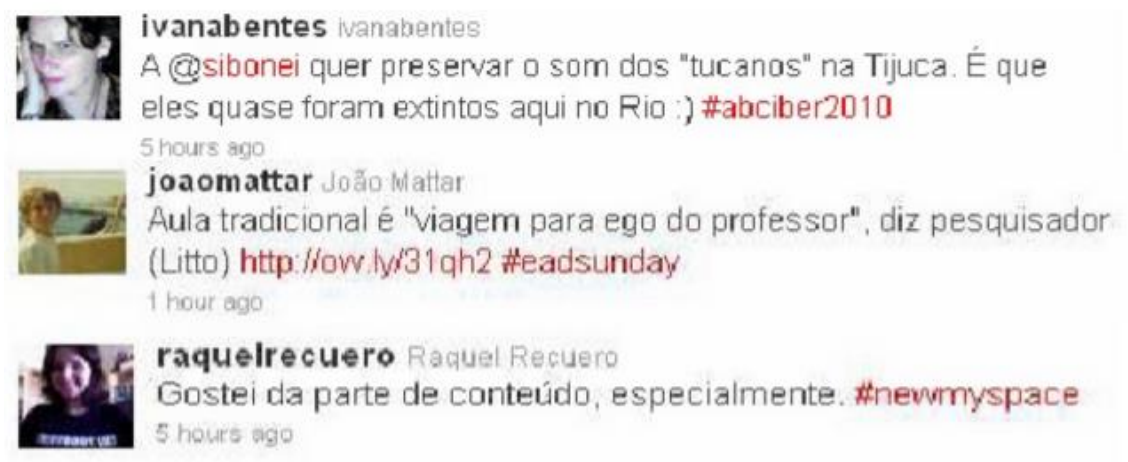

Fonte:Twitter @ivanabentes, @joaomattar e @raquelrecuero.

André Lemos (2007) aponta alguns dos princípios fundamentais para formação de comunidades, são eles:

o uso de softwares que permita discussão em grupo, a ausência de limitação em trocas de mensagens, a possibilidade de acesso para pessoas diversas, a possibilidade de deixar que os usuários resolvam seus problemas, a promoção de uma memória da comunidade (LEMOS, 2007, p. 149). 
Os recursos de reply, retweet e hashtag podem ser utilizados para a discussão em grupo, e conforme explicamos anteriormente, favorecem a comunicação multidirecional. A postagem de tweets não possui limite, podendo ser feita através de dispositivos móveis (celulares, laptops etc) ou fixos (desktop). 0 conteúdo dos tweets é totalmente de responsabilidade dos usuários, portanto, 0 administrador do site não se envolve na resolução de problemas. Além disto, todos tweets ficam gravados na página pessoal de cada usuário, registrando assim sua memória no software.

\section{Conclusões iniciais e reflexões sobre potencialidades educacionais}

A presente pesquisa, ainda em processo, não pretende esgotar o tema. Neste texto, buscamos mapear os alguns usos do Twitter por professores e pesquisadores da Cibercultura. A escolha por esses sujeitos foi proposital na medida em que os consideramos imersos na lógica da Cibercultura. Desta forma, refletindo sobre seus usos podemos compreender de que forma o desenvolvimento das redes sociais pode contribuir na construção do conhecimento.

Ao buscar a compreensão sobre os usos do Twitter pelos ciberpesquisadores, percebemos que sua interface e seus recursos (reply, retweet, hashtags) permitem um universo de potencialidades comunicacionais para seus usuários.

Para maior entendimento das relações estabelecidas entre os usos e as potencialidades comunicacionais, construímos o quadro abaixo:

Quadro 1 - Relações entre os usos e as potencialidades comunicacionais do Twitter

\begin{tabular}{|l|l|}
\hline Usos do Twitter: & Potencialidades comunicacionais: \\
\hline $\begin{array}{l}\text { Para a comunicação entre sujeitos } \\
\text { geograficamente dispersos; }\end{array}$ & Comunicação multidirecional; \\
\hline Para tornar público os relatos do cotidiano; & Comunicação Síncrona; \\
\hline Como filtro de informação; & O compartilhamento de informação; \\
\hline Para discussão sobre temas específicos; & A constituição de comunidades; \\
\hline
\end{tabular}

Fonte: 0 próprio autor. 
A partir disto, conseguimos concluir o Twitter funciona como um ambiente de diversas possibilidades, uma vez que seus usos dependem das ordens de interesse dos seus usuários. Todavia, seja qual for o interesse ao utilizá-lo, não podemos descartar o seu potencial comunicacional e dialógico. A colaboração, a troca de ideias e o compartilhamento de informações que este software social permite pode estruturar processos de construção de conhecimento coletivo através de uma comunicação multidirecional (todos-todos), voltada para as práticas da interatividade.

Dessa forma, o Twitter pode contribuir para a formação dos seus usuários na medida em que sua interface proporciona o desenvolvimento de redes sociais, onde todos os sujeitos podem expor e discutir seus pontos de vista a fim de transformar o grande número de informações que circula na rede em um conhecimento crítico sobre determinado assunto, questão ou objeto de estudo.

\section{Referências}

ABCIBER. Associação Brasileira de Pesquisadores em Cibercultura, 2010. Página inicial. Disponível em: http://abciber.org.br. Acesso em: 5 abr. 2011.

ARDOINO, J. Abordagem multirreferencial (plural) das situações educativas e formativas. In: BARBOSA, J. G. (coord.). Multirreferencialidade nas ciências e na educação. São Carlos: Editora da UFSCar, 1998. p. 24-41

CARRANO, P. C. R. Redes sociais de internet numa escola de ensino médio: entre aprendizagens mútuas e conhecimentos escolares. Revista Perspectiva, Florianópolis, v. 35, n. 2, p. 395-421, abr./jun. 2017. DOI: http://dx.doi.org/10.5007/2175-795X.2017v35n2p395.

LEMOS, A. A arte da vida: webcams e diários pessoais na internet. In: CONGRESSO BRASILEIRO DE CIÊNCIAS DA COMUNICAÇÃO, 25., 2002, Salvador. Anais [...]. Salvador: INTERCOM, 2002. Disponível em: http://www.intercom.org.br/papers/nacionais/2002/Congress02002_ Anais/2002_NP8lemos.pdf. Acesso em: 5 abr. 2011.

LEMOS, A. Cibercultura, tecnologia e vida social na cultura contemporânea. 3. ed. Porto Alegre: Sullinas, 2007

LÉVY, P. Cibercultura. São Paulo: Ed. 34, 1999.

MACEDO, R. S. O rigor hermenêutico na análise e interpretação em etnopesquisa crítica. In: OKADA, A. (org.) Cartografia cognitiva: mapas do conhecimento para pesquisa, aprendizagem e formação docente. Cuiabá: KCM, 2008. p. 43-56. 
MARTINS, A. V.; AGUIAR, L. F. Blogosfera e twittosfera: a relação entre blog e microblog. In: SIMPÓSIO NACIONAL ABCIBER, 3., 2009, São Paulo. Anais [...]. São Paulo: Abciber, 2009. Disponível em:

http://www.abciber.com.br/simposio2009/trabalhos/anais/pdf/artigos/5_jornalis mo/eixo 5_art4.pdf. Acesso em: 5 abr. 2011.

NICOLAU, M. A função múltimidiática do twitter. In: SIMPÓSIO NACIONAL ABCIBER, 3, 2009, São Paulo. Anais [...]. São Paulo: Abciber, 2009. Disponível em: http://www.abciber.com.br/simposio2009/trabalhos/anais/pdf/mesas/1_redes/eix 01_mes a2.pdf. Acesso em: 5 abr. 2011.

O'REILLY, T. What Is Web 2.0 - Design Patterns and Business Models for the Next Generation of Software. O'Reilly Publishing, 2005.

PRIMO, A. 0 aspecto relacional das interações na web 2.0. E-Compós, Brasília, v. 9, p. 1-21, 2007.

RECUERO, R. Redes sociais na internet. Porto Alegre: SULINA, 2009a. (Coleção Cibercultura).

RECUERO, R. A economia do twitter: novos apontamentos. Social media, [S. l.], 2009b. Disponível em:

http://www.raquelrecuero.com/arquivos/a_economia_do_twitter_mais_apontame ntos.html. Acesso em: 5 abr. 2011.

SANTAELLA, L.; LEMOS, R. Redes sociais digitais: a cognição conectiva do twitter. São Paulo: Paulus, 2010. (Coleção Comunicação).

SANTOS, E. O. Projeto de pesquisa: "docência na cibercultura: laboratórios de informática, computadores móveis e educação online”. Rio de Janeiro: UERJ, CNPq, 2009.

SANTOS, E. O. A informática na educação antes e depois da web 2.0: relatos de uma docente-pesquisadora. In: RANGEL, M.; FREIRE, W. Ensino aprendizagem $e$ comunicação. Rio de Janeiro: Wak Editora, 2010a. p. 107-129.

SANTOS, E. O. Projeto de pesquisa: "a cibercultura na era das redes sociais e da mobilidade: novas potencialidades para a formação de professores". Rio de Janeiro: Proped-UERJ: CNPq, 2010b.

SANTOS, E. O. Pesquisando com a mobilidade ubíqua em redes sociais da internet: um case com o twitter. ComCiencia, Campinas, 2012. Disponível em: http://www.comciencia.br/comciencia/handler.php?section=8\&edicao=74\&id=932. Acesso em: 1 mar. 2012.

ZAGO, G. Dos blogs aos microblogs: aspectos históricos, formatos e características. 2008. Disponível em: http://www.bocc.ubi.pt/pag/zago-gabriela-dos-blogs-aosmicroblogs.pdf. Acesso em: 5 abr. 2011. 
Recebido em: fevereiro de 2018

Aprovado em: junho de 2019 